\title{
DEMOCRACIA CONSTITUCIONAL: EL PAPEL DE LA JUSTICIA ELECTORAL Y EL DERECHO DE ASOCIACIÓN POLÍTICA*
}

\author{
Salvador O. NAVA GOMAR ${ }^{* *}$
}

\section{LA DEMOCRACIA CONSTITUCIONAL DELIBERATIVA}

La democracia, entendida en su acepción más simple (y conocida) como el gobierno del pueblo, es un concepto que ha acompañado la evolución del pensamiento político y jurídico por mucho tiempo (siglos) y, hoy por hoy, es un valor característico e indispensable del Estado constitucional, uno de sus elementos esenciales, no sólo como factor de legitimación del gobierno, sino también como principio normativo que prescribe conductas y orienta la interpretación jurídica.

No obstante esa permanencia en la médula del ideal jurídico-político y en la esencia del gobierno representativo, la democracia es un concepto complejo que refleja una realidad frágil e inestable; una forma de gobierno que está expuesta a sus propias contradicciones y sujeta a las exigencias de cada época; un ideal semilleno o semivacío que requiere de una realidad más sólida que lo justifique y lo complemente; esa realidad se genera y transforma a partir de la decisión política, en tanto que ésta representa la manifestación y el conducto a través del cual la autoridad ejerce sus facultades y hace valer los principios que orientan, justifican y rigen su acción.

* Ponencia presentada en el V Congreso Internacional de Derecho Electoral, realizado el 13 y 14 de noviembre de 2008, en Boca del Río, Veracruz, México.

** Magistrado de la Sala Superior del Tribunal Electoral del Poder Judicial de la Federación. El autor desea agradecer a Mauricio del Toro Huerta, secretario de Estudio y Cuenta, el apoyo en la realización del presente documento. 
Pero en la actualidad no cualquier decisión emitida por la autoridad pública es compatible con las exigencias de la democracia constitucional. Sólo es válida aquella que ha sido emitida por una autoridad competente, mediante un procedimiento previamente establecido, exponiendo las razones y fundamentos que la sustentan y que resulte compatible con los derechos y principios constitucionales, internacionales y legales. En este sentido, la dimensión normativa de la democracia es quizá la que puede ceñirse a la realidad de mejor manera, la que puede transformar el ideal democrático en práctica social y de gobierno a través de la deliberación pública y de la decisión política consecuente, y la que orienta el carácter sustantivo y normativo del texto constitucional y los derechos fundamentales internacionalmente reconocidos.

Es esta dimensión normativa de la democracia, la que se corresponde con la idea de Constitución normativa y con la función principal del texto constitucional, que en palabras de Zagrebelsky consiste en "fijar los presupuestos de la convivencia, es decir, los principios sustanciales de la vida común y las reglas del ejercicio del poder público aceptados por todos, situados por ello fuera, incluso por encima, de la batalla política; principios y reglas sobre los cuales no se vota", porque ya han sido votados de una vez por todas en su origen. ${ }^{1}$

Ello nos aproxima a la noción deliberativa de la democracia constitucional en donde la regla de la mayoría es, por sí misma, insuficiente, en tanto que han de atenderse tanto al proceso de formación de la decisión como a su contenido, a la corrección de su interpretación y su razonamiento, a su valor epistémico y a su sentido axiológico (en cuanto que el Estado constitucional tiene un compromiso con la verdad y con la justicia). ${ }^{2}$ Además, es preciso que exista también un control del resultado de la deliberación, esto es de la decisión misma.

1 Principios y votos. El Tribunal Constitucional y la politica, trad. de Manuel Martínez Neira, Madrid, Mínima Trotta, 2008, p. 29.

2 Cfr. Viola, Francesco, La democracia deliberativa entre constitucionalismo y multiculturalismo, trad. de Javier Saldaña, México, UNAM, Instituto de Investigaciones Jurídicas, 2006; Nino, Carlos, La construcción de la democracia deliberativa, Barcelona, Gedisa, 2003, y Martí, J. Luis, La república deliberativa. Una teoría de la democracia, Madrid, Marcial Pons, 2006. Sobre la relación entre constitucionalismo y verdad véase Häberle, Peter, Verdad y Estado constitucional, trad. de Guillermo José Mañón Garibay, México, UNAM, Instituto de Investigaciones Jurídicas, 2006. 
La justicia constitucional permite cierto grado de control no sólo de la Constitución sino también de la democracia deliberativa en tanto modelo de toma de decisiones políticas y de justificación o legitimación de las mismas. De hecho, como sostiene Francesco Viola, la concepción constitucional de la democracia deliberativa no se agota en el texto constitucional, ni en la asamblea parlamentaria, sino que existen diferentes sedes deliberantes que elaboran interpretaciones de los valores fundamentales y las relaboran, las corrigen, las transforman mediante una influencia mutua. ${ }^{3}$

Los tribunales constitucionales son sedes donde la deliberación pública no sólo es necesaria (diría indispensable) para delimitar la concepción del bien común y de los valores fundamentales del ordenamiento jurídico, sino también para asegurar una mayor calidad de la deliberación en la toma de decisiones y en el control de las mismas.

No entraré aquí, por razones de tiempo, a las relaciones entre los poderes Legislativo y Judicial que para mí son necesariamente complementarias para una dinámica constitucional efectiva, entre la reforma legislativa y la interpretación judicial. Aquí me limitaré a apuntar lo destacado por Owen Fiss, en el sentido de que los jueces actúan en un contexto institucional en el que sólo pueden decidir después de haber participado en un diálogo sujeto a mecanismos de control argumentativo y racional sometido a reglas procesales y a principios constitucionales, estando obligados a justificar su decisión racional y razonablemente, con lo cual se garantiza en mayor medida la objetividad de sus decisiones, respecto de aquellas emitidas por las asambleas legislativas que no actúan en ese contexto institucional. ${ }^{4}$ Lo que Robert Alexy ha identificado como la "representación argumentativa" de los tribunales frente a la tradicional representación parlamentaria. ${ }^{5}$

Lo anterior en el entendido de que, como precisa Zagrebelsky, el tribunal constitucional decide no sobre la Constitución, sino según la misma, dado que los principales problemas a los que se enfrenta la justicia

3 Cfr. Viola, Francesco, La democracia deliberativa entre constitucionalismo y multiculturalismo, cit., nota anterior, p. 81.

4 Fiss, Owen, "Las formas de la justicia", El derecho como razón pública, trad. de Esteban Restrepo, Madrid, Marcial Pons, 2007, pp. 21-76.

5 Alexy, Robert, "Ponderación, control de constitucionalidad y representación", Jueces y ponderación argumentativa, México, UNAM, Instituto de Investigaciones Jurídicas, 2006, pp. 12-18. 
constitucional son problemas de interpretación de la norma constitucional y uno de sus principales retos es garantizar la interpretación abierta y evolutiva del texto constitucional. ${ }^{6}$

Con ello quiero llamar la atención sobre el papel de los jueces constitucionales en una democracia constitucional como garantes no sólo de los derechos sino también de la apertura constitucional. En tanto que, como apunta también Víctor Ferreres, en la medida en que el sistema de justicia constitucional esté organizado de tal modo que permita la expresión de voces que no se han podido escuchar durante la deliberación parlamentaria, el proceso judicial tiene una ventaja deliberativa respecto del proceso político democrático, permitiendo así mantener viva la cultura pública constitucional y los valores que la sustentan. ${ }^{7}$

En este sentido, la democracia deliberativa constitucional que se manifiesta en la sede judicial debe procurar en la mayor medida la consideración de las razones y argumentos tanto de la mayoría parlamentaria como de aquellos individuos o grupos que no han podido participar en tales procesos legislativos o cuyas voces no han sido consideradas, particularmente la de los ciudadanos que consideran afectados sus derechos por actos de autoridad $\mathrm{u}$ otros sujetos como los partidos políticos, pero también la justicia constitucional debe velar por el interés común en la garantía efectiva de los principios constitucionales y de los derechos fundamentales.

Así entiendo la idea de democracia constitucional deliberativa. En donde la función del juez es no sólo de garante de los derechos sino de la propia dinámica constitucional, controlando, en el ámbito de su competencia, los procedimientos deliberativos de toma de decisiones y estableciendo interpretaciones plausibles y razonables de los derechos fundamentales y de los principios constitucionales.

En este mismo sentido, comparto también la tesis del mismo Francesco Viola cuando afirma que la democracia constitucional deliberativa su-

6 Zagrebelsky, Principios y votos..., cit., nota 1, p. 33. Véase también Atienza, Manuel, “Argumentación y Constitución”, en Auiló, J. et al., Fragmentos para una teoría de la Constitución, España, Iustel, 2007, pp. 113-181 y Häberle, Peter, "La sociedad abierta de los intérpretes constitucionales. Una contribución para la interpretación pluralista y 'procesal' de la Constitución", Retos actuales del Estado constitucional, Oñati, IVAP, 1996, pp. 16-46.

7 Ferreres, Víctor, Justicia constitucional y democracia, 2a. ed., Madrid, Centro de Estudios Políticos y Constitucionales, 2007, p. 161. 
pone la existencia de un derecho a la justificación argumentada, un derecho-deber a la racionalidad que los jueces deben asumir con seriedad y responsabilidad. ${ }^{8}$

\section{EL PAPEL DE LA JUSTICIA CONSTITUCIONAL ELECTORAL}

En este contexto, la justicia electoral contribuye a la democracia constitucional al menos de dos maneras: propiciando y auspiciando la deliberación constitucional en la resolución de los asuntos sometidos a su conocimiento, y definiendo el alcance normativo del propio principio democrático en su relación con otros derechos y en las restricciones que el mismo establece. Además, el derecho electoral es el escenario principal en donde operan las reglas del juego democrático, como reglas jurídicas que delimitan y reglamentan los procesos de participación política y de ejercicio efectivo de la soberanía popular a través del voto libre y secreto de la ciudadanía.

Tales reglas y principios trascienden el ámbito del ejercicio de poder estrictamente estatal e impregnan toda actividad relacionada con la cosa pública (res publica), en particular, en la materia electoral, destaca su aplicación y exigencia en la actividad de los partidos políticos, tanto en su funcionamiento externo como en su "vida interna", incluso desde el momento de su constitución.

Un claro ejemplo de lo anterior lo ilustra la tesis de jurisprudencia de la Sala Superior del Tribunal Electoral con el rubro: "ESTATUTOS DE LOS PARTIDOS POLÍTICOS. ELEMENTOS MÍNIMOS PARA CONSIDERARLOS DEMOCRÁTICOS", en la cual la Sala Superior definió el alcance de la obligación legal impuesta a los partidos políticos de establecer en sus estatutos y en su normativa partidaria procedimientos democráticos para la integración y renovación de los órganos directivos, entendiendo por democracia, no sólo su acepción gramatical "como un sistema o forma de gobierno o doctrina política favorable a la intervención del pueblo en el gobierno", sino también identificando los elementos comunes característicos de la misma, entre los que destacan, además del principio de igualdad, la garantía de ciertos derechos fundamentales básicos (principalmente, de las libertades de expresión, información y asociación) y los

8 Cfr. Viola, Francesco, La democracia deliberativa entre constitucionalismo y multiculturalismo, cit., nota 2, p. 68. 
mecanismos de control del poder, la deliberación y participación de los ciudadanos, en el mayor grado posible, en los procesos de toma de decisiones, para que respondan lo más fielmente posible a la voluntad popular. Elementos que coinciden con los rasgos y características establecidos en la Constitución General de la República y que deben ser incorporados en la vida interna de los partidos adaptándolos según su naturaleza, a fin de que no les impidan cumplir sus finalidades constitucionales. ${ }^{9}$

En el mismo sentido, dos asuntos recientes de la Sala Superior ilustran la dinámica interpretativa respecto de uno de los derechos fundamentales de todo régimen democrático, abierto y plural, como lo es el derecho de asociación en materia política. En ellos, la Sala precisó el alcance de este derecho y de su compatibilidad con el régimen democrático, lo que a su vez nos permite valorar el papel del tribunal como garante del conjunto del sistema electoral.

A) El primer asunto está relacionado con el principio democrático en la elección y permanencia de los integrantes de los órganos directivos de un partido político y corresponde al juicio para la protección de los derechos político-electorales del ciudadano SUP-JDC-517/2008, ${ }^{10}$ promovido por la agrupación política nacional "Unión Nacional Sinarquista", en contra de la resolución del Consejo General del Instituto Federal Electoral, mediante la cual le negó el registro como partido político nacional.

9 Con base en ello se determinó que los elementos mínimos de democracia que deben estar presentes en los partidos políticos son: 1. La asamblea u órgano equivalente, como principal centro decisor del partido, que deberá conformarse con todos los afiliados, o cuando no sea posible, de un gran número de delegados o representantes; 2. La protección de los derechos fundamentales de los afiliados, que garanticen el mayor grado de participación posible, como son el voto activo y pasivo en condiciones de igualdad, el derecho a la información, libertad de expresión, libre acceso y salida de los afiliados del partido; 3. El establecimiento de procedimientos disciplinarios, con las garantías procesales mínimas; 4. La existencia de procedimientos de elección donde se garanticen la igualdad en el derecho a elegir dirigentes y candidatos y la posibilidad de ser elegidos como tales; 5. Adopción de la regla de mayoría como criterio básico para la toma de decisiones dentro del partido, y 6. El establecimiento de mecanismos de control de poder, como la posibilidad de revocar a los dirigentes del partido, el endurecimiento de causas de incompatibilidad entre los distintos cargos dentro del partido o públicos y establecimiento de periodos cortos de mandato. Tesis S3ELJ 03/2005. Consultable en la Compilación Oficial de Jurisprudencia y Tesis Relevantes 1997-2005. Volumen Jurisprudencia, TEPJF, 2a. ed., 2005, pp. 120-122.

10 Sentencia del 20 de agosto de 2008. Disponible en la página electrónica del Tribunal Electoral: http://www.trife.gob.mx. 
En su sentencia, la Sala Superior confirmó dicha negativa al considerar, sustancialmente, que el artículo 35 de los estatutos propuestos contravenía de manera directa y frontal diversos aspectos de los elementos mínimos que deben satisfacer los estatutos para que sean considerados democráticos. En particular, se consideró que tal disposición al permitir la relección indefinida y la permanencia vitalicia de un solo grupo de integrantes representativos en puestos de dirección o mando de un partido político, como lo era en el caso, el Consejo Político Nacional, suponía una violación al derecho de los demás afiliados, al impedírseles ejercer su derecho de integrar y, consecuentemente, participar con carácter representativo en los órganos directivos del partido al que pertenecen, contrariamente a lo previsto en el artículo 27 , párrafo 1 , incisos b) y c), del código electoral.

La Sala consideró que para garantizar plenamente el derecho fundamental de libre asociación se requiere que los asociados tengan acceso a la toma de decisiones de los órganos que marcan las directrices y el rumbo del partido político. Lo cual no se cumple si un partido establece en sus estatutos que los miembros del máximo órgano de dirección se pueden relegir de manera indefinida o que sean inamovibles al ocupar los cargos por determinado periodo, pues al propiciar la perpetuidad de los altos cargos directivos partidarios se suplanta a las bases y se deslegitima a los dirigentes porque se imponen a los militantes, cuando que éstos deben ser siempre electos mediante mecanismos democráticos ordinariamente directos y sólo excepcionalmente indirectos, pero además renovables periódicamente, lo que entraña que la relección en caso de establecerse, no puede ser tal que haga nugatorios los derechos de los agremiados a elegir de entre distintas opciones a otros miembros como sus directivos y a postularse para ser electos en esos mismos cargos, siendo que en el caso se trataba del órgano partidario que tenía las atribuciones necesarias para adoptar las decisiones de mayor trascendencia en la vida interna y externa del instituto político que se pretendía constituir.

Además, se consideró que la relección indefinida y la permanencia vitalicia para los miembros del Consejo Político Nacional, es contraria a la obligación de los partidos políticos de sujetar sus actividades dentro de los cauces legales y ajustar sus conductas y la de sus militantes a los principios del Estado democrático, al crear cotos exclusivos de poder y zonas de inmunidad dentro del propio instituto político, en violación a 
los principios de igualdad y legalidad, y en contravención de los fines para los cuales fueron creados los partidos políticos.

B) El segundo caso que quiero destacar corresponde a los juicios acumulados SUP-JDC-2665/2008 y SUP-JDC-2670/2008, ${ }^{11}$ en los cuales la Sala Superior se pronunció sobre un aspecto medular en todo régimen democrático como es el alcance de la libertad de asociación y afiliación a los partidos políticos a partir de la prohibición de afiliaciones corporativas o colectivas. Importancia manifiesta en la incorporación expresa de dicha prohibición en la reciente reforma al artículo 41 constitucional.

Los juicios fueron promovidos por ciudadanos vinculados a la agrupación política "Rumbo a la Democracia", entre ellos sus representantes, en contra de la resolución del Consejo General del Instituto Federal Electoral (emitida en cumplimiento de una sentencia previa de la Sala Superior) en la que se determinó improcedente el otorgamiento de su registro como partido político nacional.

La Sala Superior (por mayoría de cinco votos contra dos) confirmó dicha determinación al considerar que se actualizaba la prohibición de injerencia gremial prevista por el artículo 41, base 1, párrafo 2, de la Constitución Política de los Estados Unidos Mexicanos, donde expresamente se indica: “... quedan prohibidas la intervención de organizaciones gremiales o con objeto social diferente en la creación de partidos y cualquier forma de afiliación corporativa".

En la sentencia, después de considerar el desarrollo histórico del derecho de asociación en materia política y el texto actual del artículo 41 constitucional, la Sala Superior confirmó la intención constituyente de garantizar la libre afiliación individual a los institutos políticos, a través de la prohibición de afiliaciones corporativas o colectiva, así como la necesidad de impedir, en la creación y registro de los partidos políticos, toda injerencia de organizaciones gremiales o con objeto distinto. De hecho, la reciente reforma constitucional explicitó el ámbito prohibitivo en dos vertientes básicas: a) prohibición de afiliación corporativa, y b) intervención gremial.

Esta doble prohibición garantiza el derecho individual de libre asociación, así como que en la creación y formación de los partidos políticos no intervenga ninguna organización gremial o cualquier otra que tenga un fin distinto al de las organizaciones de ciudadanos que pretendan participar en la vida política y democrática del país.

11 Sentencia del 1o. de octubre de 2008. Disponible en http://www.trife.gob.mx 
En este sentido, la restricción constitucional de intervención, que alude a tomar parte en un asunto, y con ello implica la acción de mediar, interceder o interponerse, debe materializarse mediante un actuar positivo, que en el caso se habría acreditado plenamente por la responsable en su resolución, a través de diversos actos concretos de dirigentes y agremiados de dos sindicatos.

En especial, la autoridad administrativa electoral no se limitó a considerar el hecho de que los dirigentes del Sindicato Nacional de Trabajadores de Autotransportes, Similares y Conexos de la República Mexicana y la Unión de Trabajadores de la Industria de la Construcción, Actividades Similares y Conexas de la República Mexicana, fueran simultáneamente quienes llevaron a cabo el trámite correspondiente al proceso de creación del partido político ante la autoridad administrativa electoral, sino que se acreditó que tales personas intervinieron por medio de actos concretos y específicos en el proceso de creación del partido político nacional "Partido Mexicano Rumbo a la Democracia", así como por la utilización del patrimonio sindical en el proceso de constitución del nuevo partido político, tanto a través de aportaciones en efectivo, como mediante "actos de comodato", equiparables a una aportación en especie, e inclusive a través de un "programa de afiliación" tendente a reclutar afiliados a la agrupación política nacional "Rumbo a la Democracia". Todo lo cual llevó a la Sala Superior a confirmar los argumentos del Instituto Federal Electoral y a puntualizar que, en el contexto del caso, los actos de representación podían considerarse válidamente como una "intervención gremial".

Finalmente, la Sala Superior desestimó los argumentos de los actores en el sentido de que la negativa de su solicitud de registro como partido político vulneraba sus derechos de asociación y afiliación, reconocidos en la Constitución y en diversos instrumentos internacionales, toda vez que el derecho de libre asociación (en su vertiente de afiliación a un partido político), tal como está previsto constitucionalmente supone que en el ejercicio del mismo "no se verifique ningún acto ya sea de afiliación corporativa e intervención gremial", con lo cual se privilegia la libertad e individualidad del derecho de asociación como parámetros necesarios para garantizar que ese derecho se preserve particularmente a los ciudadanos y no se extienda a grupos o corporaciones de carácter profesional de alguna índole, lo cual es compatible con los tratados internacionales. 


\section{COMENTARIO FINAL}

Los ejemplos expuestos, junto con otros casos resueltos por la Sala Superior en donde se han precisado los alcances de los derechos político-electorales; de la libertad de expresión en materia electoral; del secreto profesional de los periodistas en procedimientos administrativos sancionadores o del régimen de transparencia de los partidos políticos respecto de sus militantes, ilustran cómo a través de sus sentencias el Tribunal Electoral del Poder Judicial de la Federación y en particular su Sala Superior, contribuye a la deliberación pública y a la determinación del sentido de los valores constitucionales y del propio régimen democrático, con lo cual contribuye también a materializar los postulados teóricos de la democracia constitucional.

No podremos ver jamás el rostro completo de un régimen democrático y no podremos verlo porque las sociedades se transforman, son móviles y los tiempos no permiten fotografías estáticas, los tiempos de hoy son inciertos, líquidos, cambiantes, por eso sólo podemos conocer su dinámica, sus formas pasajeras y elaborar nuestro juicio a partir de esa dinámica, de ese rostro visible y posible. La democracia constitucional no se agota en su dimensión institucional y normativa (identificada por Ferrajoli como ese complejo y frágil sistema de reglas, vínculos y equilibrios que garantizan el pacto de convivencia basado en la igualdad en derechos y oportunidades en un contexto de libertad), ${ }^{12}$ se expresa también en su dimensión práctica, a través de los razonamientos que sustentan las decisiones públicas que, en última instancia, la hacen posible.

Una de esas formas en que se expresa la deliberación democrática es a través de las sentencias judiciales que concretizan los valores constitucionales, garantizan los derechos fundamentales y los principios del Estado democrático. Esta es la alta responsabilidad de los tribunales constitucionales y es también el compromiso que hemos adoptado en el Tribunal Electoral, el de expresar de manera justificada nuestras razones jurídicas y el de exponerlas al debate público abierto para confrontar sus argumentos y, en su caso, confirmar la corrección de su razonamiento y la justicia de su determinación.

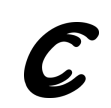

12 Cfr. Ferrajoli, Luigi, El garantismo y la filosofía del derecho, Colombia, Universidad Externado de Colombia, 2000, pp. 154 y ss. 